\title{
The rule of the front and behind top edges of weirs on their hydraulic performance and working efficiency
}

\author{
Mohamed A. Ashour ${ }^{1}$, Tarek S. Abu-Zeid ${ }^{1 *}$, Radwa Hassan ${ }^{2}$ \\ ${ }^{1}$ Department of Civil Engineering, Faculty of Engineering, Assiut University, 71515 Assiut, Egypt, e-mail: mashour475275@yahoo.com; \\ tareksayed1986@gmail.com $\left({ }^{*}\right.$ corresponding author) \\ ${ }^{2}$ Water Holding Company, Assiut, Egypt
}

\begin{abstract}
The geometry of weirs is a prime factor influencing hydraulic performance and accuracy. One of the geometric components of weirs, is the situation of its top corners, are they sharp or rounded, and what is the most suitable radius of such rounding curves? The present study was conducted to examine the effect of using five different radius of curvature for both the upstream and downstream top corners of a clear over-fall weir on its hydraulic performance and accuracy. Eleven models of wooden weirs were shaped and prepared with five different values of rounding curvature. The prepared weir models were located in a laboratory tilting flume of $13.50 \mathrm{~m}$ length, $0.30 \mathrm{~m}$ width, and $0.30 \mathrm{~m}$ depth. The study was carried out in the Irrigation and Hydraulic Laboratory of the Civil Department, Faculty of Engineering, Assiut University, Egypt. A discharge ranging from 2.0 to $22.0 \mathrm{dm}^{3} \mathrm{~s}^{-1}$ was used, and through 66 experimental runs, all the necessary hydraulic parameters were measured, and recorded. The obtained data were tabulated, analyzed, plotted, and technically discussed. The main results and obtained conclusions proved that when the front weir top edge is curved the discharge coefficient increases up to $8 \%$. Also, when both front, and behind weir top edges are curved the discharge coefficient increases up to $14 \%$. At the same time the discharge coefficient has a maximum value when the radius of curvature in upstream and downstream top corners equals $20 \%$ of the height of the weir.
\end{abstract}

Key words: discharge coefficient, clear over-fall weir, radius of curvature, hydraulic performance

\section{Introduction}

Nowadays, Egypt is facing a serious problem concerning water. The expected decrease in the water quantity of the Nile, in the light of the disagreement of the countries of the Nile basin over Egypt's historical water share is the main challenge Egypt, and Egyptians have to overcome through all possible methods. In addition to the diplomatic and political negotiations with the Nile basin countries, a review of our traditional approach to irrigation and the irrigation systems used as well as the applied water duties for different crops, must be carried out to avoid the unacceptable overuse of irrigation water. At the same time, improving the efficiency of transporting, distributing, and controlling irrigation water is of great importance because saving high quantities of water may play a significant role in solving the problem of water shortage. Simultaneously, if more care is taken to optimize the efficient reuse of agricultural drainage water and suitable ratios for safely mixing it with fresh water are adopted, more water would be available for irrigation purposes. Since, as mentioned previously, con- trol, transport and distribution of the available limited quantity of water is one of the most effective parameters in water saving, our attention must orient towards the constructions and tools that are used in measuring and controlling the flow in open channels.

This study deals with the clear over-fall weir as one of the simplest, least expensive, oldest, and most accurate structures used for measuring and distributing irrigation water in open channels, in Egypt and all over the world. Owing to the above-mentioned advantages of weirs, over the years many researchers and investigators have carried out numerous studies and experiments for improving the hydraulic performance of weirs and optimizing their measuring efficiency and accuracy, such as Ghazizadeh and Moghaddam (2016), Parsaie et al. (2016), Arvanaghi and Mahtabi (2015), Caroline and Afshar (2014), Jalil et al. (2014), Abou-Rehim (1991), Ashour (1974), Leliavsky (1959), Cline (1935).

Circular weirs were common in the late 19th and early 20th centuries. During the 19th century, efforts were made to increase the drainage capacity of overflows. These efforts resulted in the emergence of cir- 
cular weir designs; Bazin (1898) was the first to study the flow characteristics of broad-crested weirs, which was later used by Creager (1917) to develop the profile of ogee spillways. Creager (1917) also conducted some studies on the profile of circular weirs. Woodburn (1932) showed that when the upstream corner of a weir is curved, the discharge coefficient increased up to $8 \%$. Henderson (1966) developed an equation to determine the discharge coefficient for round corner weirs with a critical flow condition as follows:

$$
Q=2 / 3 C_{d}(2 \mathrm{~g})^{0.5} \mathrm{~L} \mathrm{H}^{1.5} .
$$

Ramamurthy and Vo (1993a,b) tried to improve the discharge coefficient by providing different upstream and downstream slopes for circular-crested weirs. Amin (2005) experimentally investigated the most suitable shape of a weir to achieve the maximum discharge coefficient. He found that curved weirs produced the maximum discharge and that the discharge coefficient depends mainly on the ratio $\left(H_{w} / p\right) \times F_{r}$ and the submersion ratio. Al-Babely et al. (2011) showed that the increase in the ratio of head to weir radius ratio $\left(H_{w} / R\right)$ value caused an increase in the discharge coefficient $\left(C_{d}\right)$ value for the same height of weir. Schmocker et al. (2011) showed that the upstream weir face angle has only a small effect on the discharge coefficient. In contrast, increasing the downstream weir face angle increased the discharge coefficient. Riyadh (2013) estimated that the discharge coefficient decreased with the head upstream and the weir crest increased; the height and degree of curvature of over flowing has a significant influence on $\left(C_{d}\right)$ and the discharge coefficient increased if the streamlining of the curvature increases. Madadi et al. (2013) observed that the curvature at the upstream edge of a weir allows water to flow more easily and increases the discharge capacity. Haghiabi (2012) developed an equation indicat-

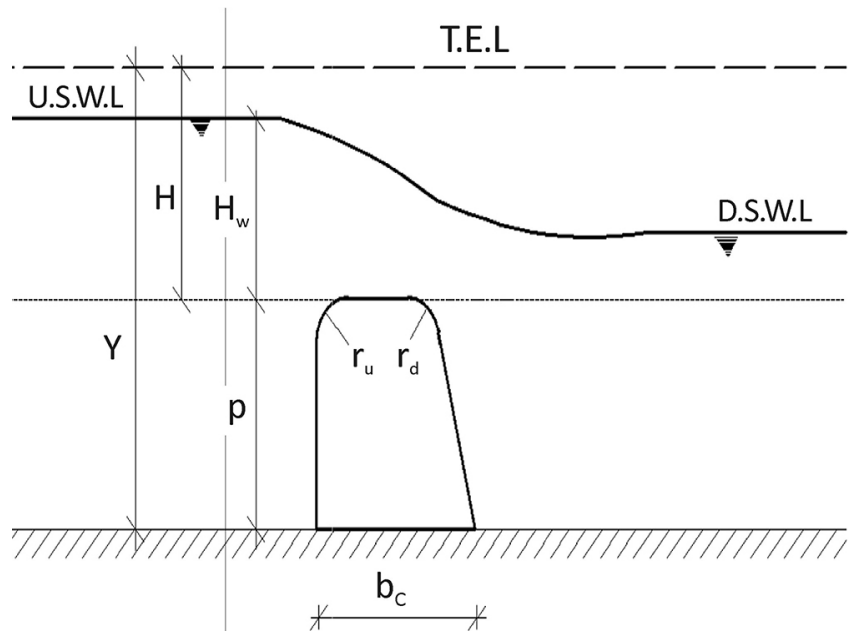

Fig. 1. Definition sketch for flow over clear over fall weir ing that the hydraulic characteristics of a circular crested weir depend only on the dimensionless total upstream head $\left(H_{w} / R\right)$ and independent of weir height $(p)$. Kumar et al. (2013) formulated a generalized equation for $C_{d}$ for curved weirs which can be used to find $C_{d}$ for any value of $(\theta)$ in the corresponding specified range and hence the discharge, as follows:

$$
\begin{gathered}
C_{d}=\left(-0.171 \theta^{2}+0.403 \theta-0.623\right)+ \\
\left(0.266 \theta^{2}-0.724 \theta+0.055\right)(h / w) .
\end{gathered}
$$

\section{Materials and methods}

\section{Dimensional Analysis}

The relevant parameters in the study of a clear overfall weir as shown in the Figure 1, come from the following groups:

- (A) Fluid properties and physical constants: the density of water $\rho\left(\mathrm{kg} \mathrm{m}^{-3}\right)$, the dynamic viscosity of water $\mu\left(\mathrm{N} \mathrm{s} \mathrm{m}^{-2}\right)$, the surface tension of water $\sigma\left(\mathrm{N} \mathrm{m}^{-1}\right)$ and the acceleration of gravity $g\left(\mathrm{~m} \mathrm{~s}^{-2}\right)$;

- (B) Channel geometry: the channel width $b(\mathrm{~m})$;

- (C) Weir geometry: the upstream top edge radius of curvature $r_{u}(\mathrm{~m})$, the downstream top edge radius of curvature $r_{d}(\mathrm{~m})$, and the crest height above the channel bed $p(\mathrm{~m})$;

- (D) Upstream flow properties: the depth of flow over the weir crest $H_{w}(\mathrm{~m})$, and discharge per unit width $q\left(\mathrm{~m}^{3} \mathrm{~s}^{-1} \mathrm{~m}^{-1}\right)$.

Taking into account all the above parameters, dimensional analysis yields:

$$
\emptyset_{1}=\left(\rho, g, \mu, r_{u}, r_{d}, H_{w}, \sigma, p, q\right) .
$$

The above variables give the following dimensionless numbers:

$$
C_{d}=\varnothing_{2}\left[\left(r_{u} / H_{w}\right),\left(r_{d} / H_{w}\right),\left(p / H_{w}\right), R_{e}, F_{r}, W_{e}\right] .
$$

Any combination of these numbers is also dimensionless and may be used to replace one of the form of the above considerations. The relationship may be rewritten in terms of dimensionless parameters:

$$
C_{d}=\varnothing_{3}\left[\left(r_{u} / H_{w}\right),\left(r_{d} / H_{w}\right),\left(p / H_{w}\right), F_{r}\right] \text {. }
$$

\section{Experimental set-up}

Experiments were performed in a re-circulation, rectangular open tilting flume at the Irrigation and Hydraulic laboratory of the Civil Engineering Department at Assiut University, Egypt. As shown in Figure 2, the flume is $13.50 \mathrm{~m}$ long, $0.30 \mathrm{~m}$ wide and $0.30 \mathrm{~m}$ deep, 


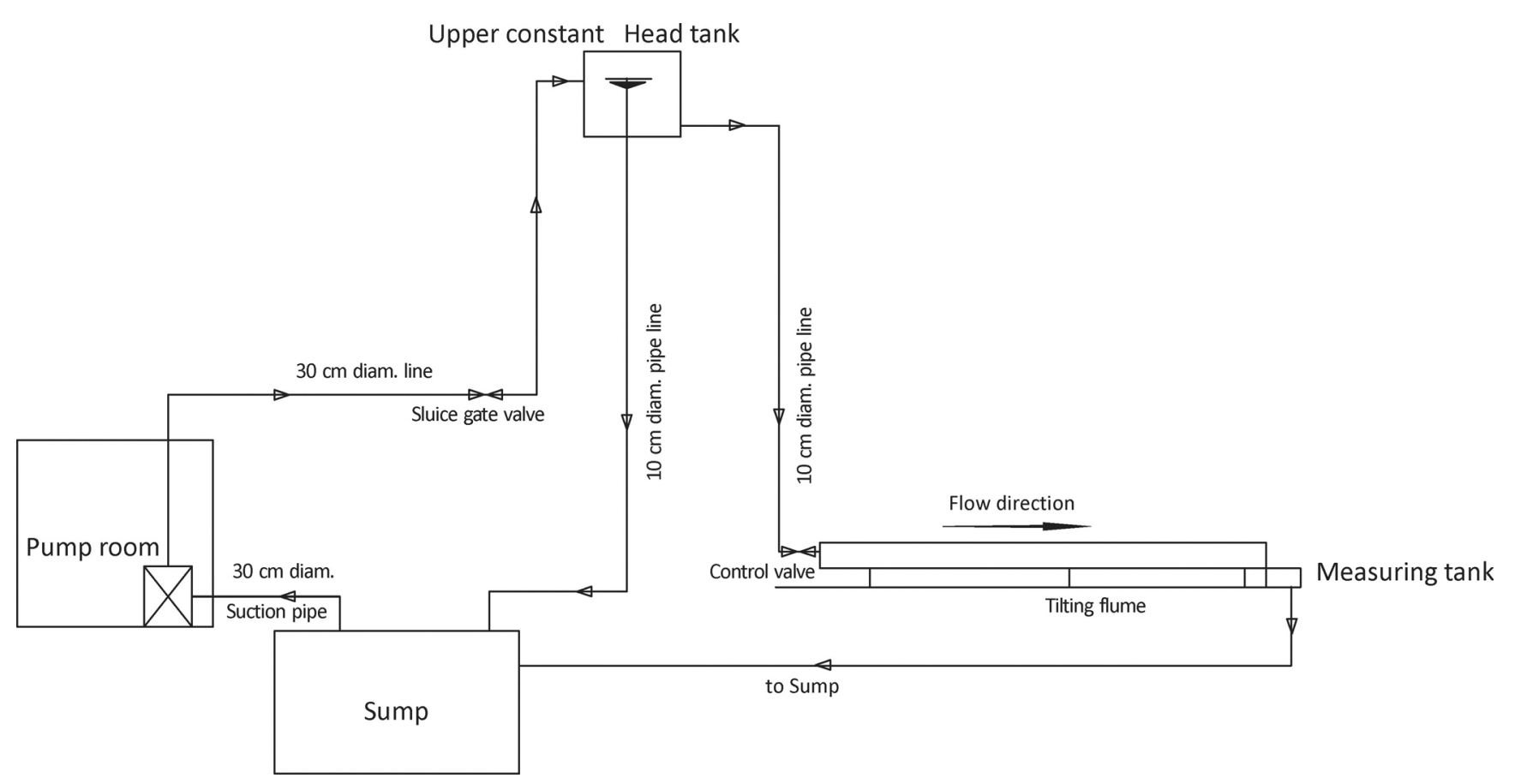

Fig. 2. Schematic diagram of water recirculation in the laboratory

with an adjustable slope. The discharge was delivered by a pump and measured using a calibrated orifice meter with a manometer. Measurements of water depth were recorded using an electrical point gauge mounted on an aluminum frame over the channel so it could be moved longitudinally and transversely over the channel. The gauge was equipped with a Vernier, readable to reach an accuracy of about $0.10 \mathrm{~mm}$. Eleven models of wooden weirs were shaped and prepared with five different values of rounding curvature as shown in Table 1 . The tail gate was located at the end of the channel to control the downstream water depth.

\section{Experimental approach}

The prepared weir models were located in a laboratory tilting flume of $13.50 \mathrm{~m}$ length, $0.30 \mathrm{~m}$ width, and $0.30 \mathrm{~m}$ depth. Detailed dimensions and arrangements of the tested weir models are shown in Table 1. A discharge range from 2.0 to $22.0 \mathrm{dm}^{3} \mathrm{~s}^{-1}$ was used, 66 runs were conducted and were categorized into three sets of experiments. The first set of experimental runs was carried out using a model of a weir without any rounding curvature of the front or the behind corners of its top edge. This set included six runs, and was considered as a reference in order to estimate the effect of using the tested weirs. The second set of experimental runs was carried out using models of weir having five values of rounding curvature in upstream $\left(r_{u} / p=0.1,0.2,0.3,0.4\right.$, 0.5 ) and without any rounding curvature of the behind corners of its top edge. This set included 30 runs. The third set of experimental runs was carried out using the most effective shape obtained from the aforementioned step to examine its efficiency in increasing the discharge coefficient, and at the same time to achieve the best value of rounding curvature in downstream. This set included 30 runs. In each test, six different discharges between 2.0 and $22.0 \mathrm{dm}^{3} \mathrm{~s}^{-1}$ were used.

\section{Experimental procedures}

Runs were started with the models fixed separately on the bed of the flume. The storage, feeding tank was filled with water. The intake valve of feeding pipeline was opened slowly to give a definite value of discharge through adjusting both the intake valve and the water manometer reading. The downstream tail gate was adjusted to obtain the free flow conditions, after a period of about 20 to 30 minutes. The measurements of water depth upstream and downstream of the weir model were taken using an electrical point gauge mounted on an aluminum frame over the channel. Calibration procedures followed those recommended by the manufacturer.

\section{Results and analysis}

In order to find the most effective radius of curvature of the top corners of a clear over-fall weir for improving the discharge coefficient, a series of runs are performed on ten models of weir, in addition to the sharp one as a reference, as given in our previous paper (Ashour et al. 2016) and shown in Table 1. To study the effect of rounding the curvature of the top corners on 
Table 1. Tested configuration of the weirs

\begin{tabular}{|c|c|c|c|c|c|}
\hline $\begin{array}{c}\text { Model } \\
\text { number }\end{array}$ & Cross section of the model & $\begin{array}{c}\text { Model } \\
\text { number }\end{array}$ & Cross section of the model & $\begin{array}{c}\text { Model } \\
\text { number }\end{array}$ & Cross section of the model \\
\hline \multirow[t]{2}{*}{ Model 1} & & Model 2 & & Model 3 & \\
\hline & $r_{/} / p=0$ & & $r_{d} / p=0.1$ & & $r_{d} / p=0.2$ \\
\hline \multirow[t]{2}{*}{ Model 4} & & Model 5 & & Model 6 & \\
\hline & $r_{\sqrt{ } / p} p=0.3$ & & $r_{/} / p=0.4$ & & $r_{J} / p=0.5$ \\
\hline \multirow[t]{2}{*}{ Model 7} & & Model 8 & & Model 9 & \\
\hline & $r_{u} / p=0.2$ & & $r_{d} / p=0.2$ & & $r_{d} / p=0.3$ \\
\hline \multirow[t]{2}{*}{ Model 10} & & Model 11 & & & \\
\hline & $r_{d} / p=0.4$ & & $r_{u} / p=0.2$ & & \\
\hline
\end{tabular}

the discharge coefficient, the water depths were measured upstream and downstream after the flow had become steady and the hydraulic jump had fully occurred on the floor downstream of the weir model. Analysis and the discussion procedure were performed through addressing the following points:

Firstly: Experiments carried out for testing the effect of the front weir top edge curvature $\left(r_{u} / p=0.1,0.2,0.3\right.$, $0.4,0.5)$ on the discharge coefficient, with different discharges;

Secondly: After choosing the most effective radius of the front weir top edge that gives the maximum discharge coefficient from the aforementioned step, experiments are carried out for testing the effect of the behind weir top edge curvature on the discharge coefficient $\left(r_{d} / p=0.1,0.2,0.3,0.4,0.5\right)$.

\section{Testing the effect of the front weir top edge curvature on the discharge coefficient}

A. Relations between the discharge coefficient $\left(C_{d}\right)$ and the ratio between head over the crest and the height of weir $\left(H_{w} / p\right)$

The discharge coefficient $\left(C_{d}\right)$ was plotted versus the ratio between head over the crest and the height of weir $\left(H_{w} / p\right)$ for the different tested weirs. The ratio between the curvature of the front weir top edge and the height of weir $\left(r_{u} / p\right)$ are plotted as a third dimension, as shown in Figure 3.

Figure 3 presents a comparison between models having curvature of the front weir top edge and a sharp one. From this figure it is clear that the curved weirs are more efficient in increasing the discharge coefficient $\left(C_{d}\right)$ than the sharp one. Also, increasing the ratio between head over the crest and the height of weir $\left(H_{w} / p\right)$ increases the discharge coefficient $\left(C_{d}\right)$.

From the figure it can be seen that the curvature of the front weir top edge allows water to flow more easily and increases the discharge capacity. Also, for a certain value for the ratio $\left(H_{w} / p\right)$ the $C_{d}$ was observed give a maximum value when the radius of curvature of the front weir top edge was equal to $20 \%$ of the height of the weir.

For $\left(H_{w} / p \leq 0.6\right)$, it is clear that the discharge coefficient $\left(C_{d}\right)$ increases slightly, while for $\left(H_{w} / p>0.6\right)$ the discharge coefficient $\left(C_{d}\right)$ tangibility increases. This is due to, at high values of discharges, turbulent downstream head structure decrease, and the hydraulic is jump formed, somewhat nearer to the head structure due to the increase of the initial depth of the formed hydraulic jump.

Based on the experimental data and using the simple and multiple linear regression analysis, the best equation for predicting the discharge coefficient $\left(C_{d}\right)$ for round corner weirs as a function of the ratio between head over the crest and the height of weir $\left(H_{w} / p\right)$ can be written in the following form:

$$
C_{d}=\mathrm{A}\left(H_{w} / p\right)^{2}-\mathrm{B}\left(H_{w} / p\right)+\mathrm{C},
$$




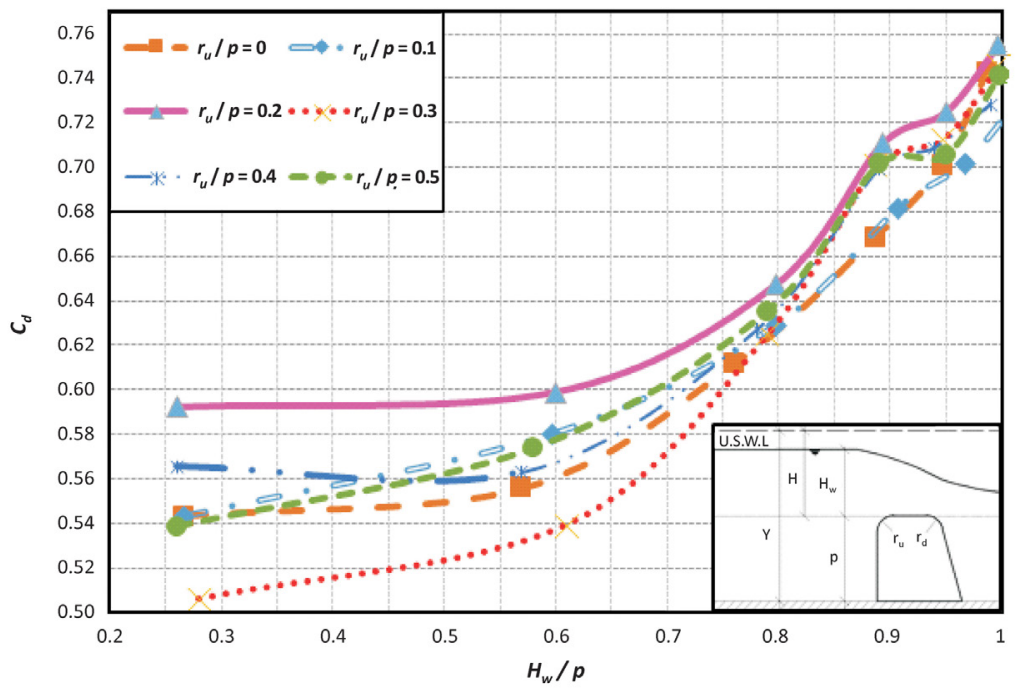

Fig. 3. Relationship between the discharge coefficient $\left(C_{d}\right)$ and the ratio between head over the crest and the height of weir $\left(H_{w} / p\right)$ for different tested weirs

in which (A, B and $\mathrm{C}$ ) are coefficients depending on the radius of curvature for the front weir top edge. Their values are given in Table 2, as well as the different values of correlation factor.

Table 2. Values of coefficients $A, B$ and $C$ in Equation 6

\begin{tabular}{ccccccc}
\hline Ratio of $r_{/} / p$ & 0.0 & 0.1 & 0.2 & 0.3 & 0.4 & 0.5 \\
\hline $\mathrm{A}$ & 0.567 & 0.351 & 0.5231 & 0.542 & 0.5308 & 0.384 \\
\hline $\mathrm{B}$ & 0.447 & 0.2033 & 0.435 & 0.343 & 0.4233 & 0.209 \\
\hline $\mathrm{C}$ & 0.623 & 0.573 & 0.670 & 0.556 & 0.637 & 0.566 \\
\hline $\mathrm{R}^{2}$ & 0.995 & 0.997 & 0.989 & 0.986 & 0.982 & 0.987 \\
\hline
\end{tabular}

B. Relations between the discharge coefficient $\left(C_{d}\right)$ and the discharge $(Q)$

The relationship between the discharge coefficient $\left(C_{d}\right)$ and the discharge $(Q)$ for all models under study having curvature of the front weir top edge and the sharp one is presented in Figure 4. This figure shows the percentage of increase in the discharge coefficient $\left(C_{d}\right)$, using different radius of curvature of the top corners of a clear over-fall weir to be more than that obtained using the sharp one. It is clear that at the same value of discharge $(Q)$, the model having the radius of curvature equal $20 \%$ of the height of weir gives the maximum value of the discharge coefficient $\left(C_{d}\right)$. For comparison purposes Table 3 was constructed, including the ob-

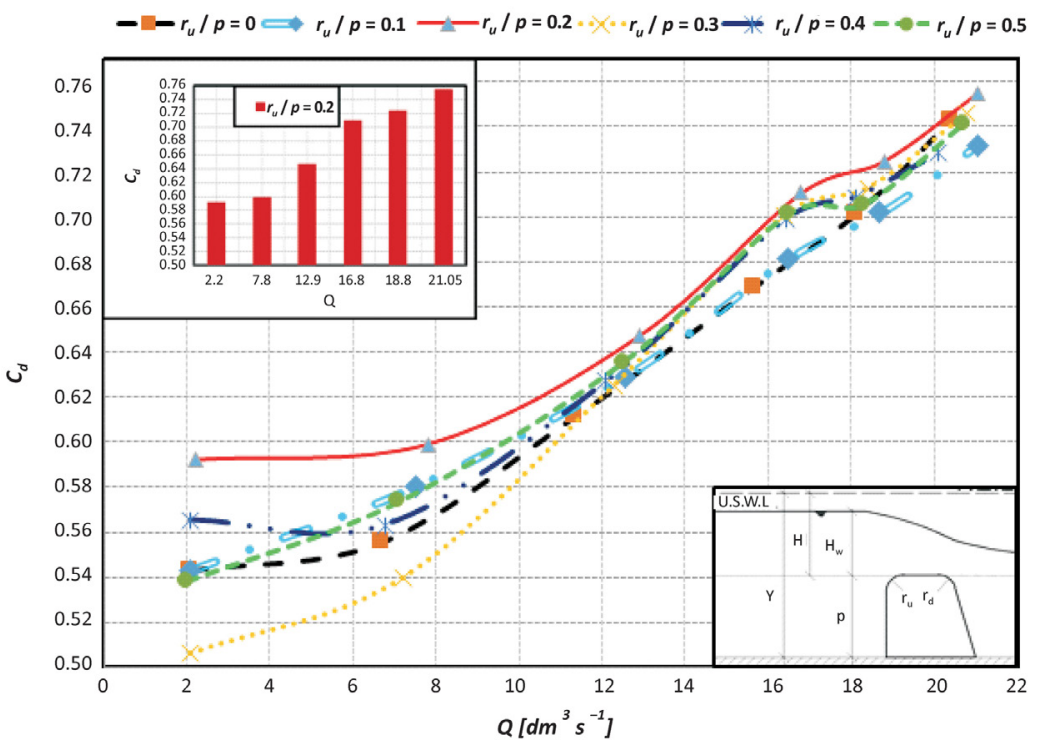

Fig. 4. Relationship between the discharge coefficient $\left(C_{d}\right)$ and the discharge $(Q)$, for different tested weirs 
Table 3. Effect of curvature of the front weir top edge on the discharge coefficient $\left(C_{d}\right)$ compared with using the sharp one

\begin{tabular}{|c|c|c|c|c|c|c|c|}
\hline \multirow{2}{*}{ Ratio of $r_{d} / p$} & \multicolumn{6}{|c|}{ Discharge coefficient $C_{d}$ for different values of $Q\left[\mathrm{dm}^{3} \mathrm{~s}^{-1}\right]$} & \multirow{2}{*}{$C_{d}$ increase [in \%] } \\
\hline & $Q=2.1$ & $Q=7.5$ & $Q=12.5$ & $Q=16.5$ & $Q=17.5$ & $Q=21$ & \\
\hline 0.0 & 0.543 & 0.555 & 0.611 & 0.668 & 0.701 & 0.743 & reference \\
\hline 0.1 & 0.543 & 0.580 & 0.629 & 0.682 & 0.702 & 0.732 & $1.90-2.80$ \\
\hline 0.2 & 0.552 & 0.599 & 0.647 & 0.710 & 0.724 & 0.754 & $1.58-7.80$ \\
\hline 0.3 & 0.506 & 0.539 & 0.625 & 0.701 & 0.712 & 0.746 & $0.00-4.00$ \\
\hline 0.4 & 0.565 & 0.563 & 0.627 & 0.699 & 0.709 & 0.729 & $1.30-4.59$ \\
\hline 0.5 & 0.538 & 0.574 & 0.635 & 0.701 & 0.705 & 0.741 & $0.00-4.89$ \\
\hline
\end{tabular}

tained values of the percentage of increase in the discharge coefficient $\left(C_{d}\right)$ using different curvature of the front weir top edge more than the sharp one. From the Table 3, it is clear that:

- For all studied discharges, the weirs with curvature of the front top edge are more effective than the sharp one in increasing the discharge coefficient $\left(C_{d}\right)$;

- The model of the weir with the radius of curvature equal to $20 \%$ of the height of the weir gives the maximum value of the discharge coefficient $\left(C_{d}\right)$;

- Increasing the ratio between the radius of curvature and the height of a weir more than $20 \%$, decreases the value of the discharge coefficient $\left(C_{d}\right)$;

- When the front top edge of the weir is curved, the discharge coefficient increased up to $8 \%$, which agrees with the results of Schmocker et al. (2011) and Woodburn (1932).

C. Relations between the discharge coefficient $\left(C_{d}\right)$ and the ratio between head over crest and curvature at upstream $\left(H_{w} / r_{u}\right)$

The relationship between the discharge coefficient $\left(C_{d}\right)$ and the ratio between head over the crest and the radius of curvature of the front weir top edge $\left(H_{w} / r_{u}\right)$ for the model of weir having the radius of curvature equal $20 \%$ of the height of weir is shown in Figure 5. From this figure it is clear that the discharge coefficient increases with the increase of the ratio between head over the crest and the radius of curvature of the weir $\left(H_{w} / r_{u}\right)$. Also, for a further increase of the ratio between head over the crest and the radius of curvature of the weir $\left(H_{w} / r_{u}\right)$ the percentage of increase in the discharge coefficient increases.

Based on the experimental data and using the simple and multiple linear regression analysis, the best equation for predicting the discharge coefficient $\left(C_{d}\right)$ for round corner weirs as a function of the ratio between head over the crest and the radius of curvature of the front weir top edge $\left(H_{w} / r_{u}\right)$ can be written in the following form:

$$
C_{d}=\mathrm{A}\left(H_{w} / r_{u}\right)^{2}-\mathrm{B}\left(H_{w} / r_{u}\right)+\mathrm{C},(7)
$$

in which (A, B and C) are coefficients dependent on the radius of curvature of the front weir top edge. Their values are given in Table 4, as well as the different values of the correlation factor.

Table 4. Values of coefficients $A, B$ and $C$ in Equation 7

\begin{tabular}{cccccc}
\hline Ratio of $r_{J} / p$ & 0.1 & 0.2 & 0.3 & 0.4 & 0.5 \\
\hline A & 0.0035 & 0.0209 & 0.0488 & 0.0849 & 0.0962 \\
\hline B & 0.2030 & 0.0871 & 0.1028 & 0.1693 & 0.1045 \\
\hline C & 0.5731 & 0.6703 & 0.5569 & 0.6377 & 0.5663 \\
\hline $\mathrm{R}^{2}$ & 0.997 & 0.990 & 0.986 & 0.982 & 0.988
\end{tabular}

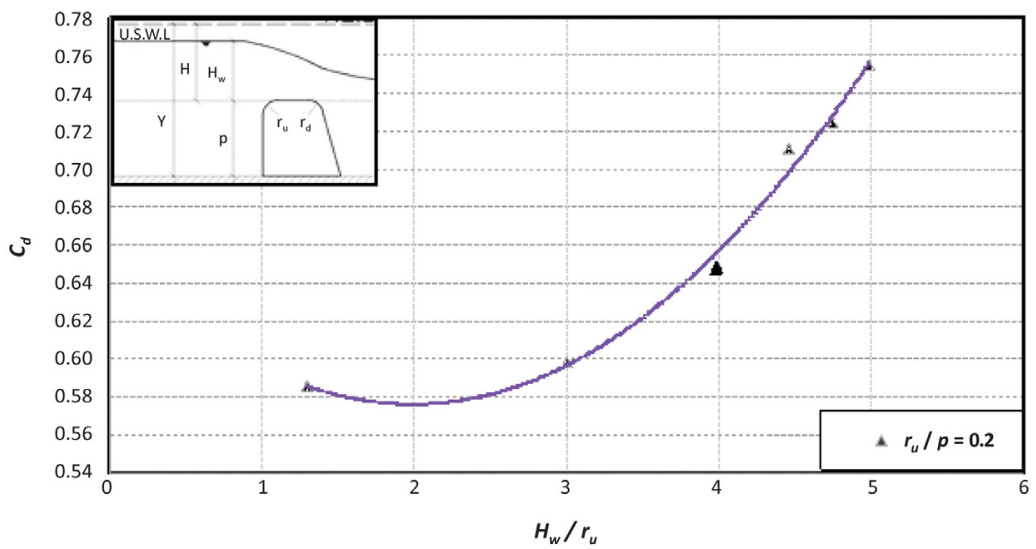

Fig. 5. Relationship between the discharge coefficient $\left(C_{d}\right)$ and the ratio between head over the crest and the radius of curvature of weir $\left(H_{w} / r_{u}\right)$ 


\section{Testing the effect of the behind weir top edge on the discharge coefficient}

After achieving the most effective radius of curvature of the front weir top edge that gives the maximum discharge coefficient from the aforementioned step, experiments were carried out using the model with a radius of curvature of the front weir top edge equal to $20 \%$ of the height of weir, for testing the effect of the curvature of the behind weir top edge on the discharge coefficient $\left(r_{d} / p=0.1,0.2,0.3,0.4,0.5\right)$ with different discharges.

A. Relations between the discharge coefficient $\left(C_{d}\right)$ and the ratio between head over the crest and the height of weir $\left(H_{w} / p\right)$

The discharge coefficient $\left(C_{d}\right)$ was plotted versus the ratio between head over the crest and the height of weir $\left(H_{w} / p\right)$ for different tested weirs. The ratio between the curvature of the behind weir top edge and the height of weir $\left(r_{d} / p\right)$ are plotted as a third dimension, as shown in Figure 6.

From this figure it is clear that the increase in the ratio between head over the crest and the height of weir $\left(H_{w} / p\right)$ increases the discharge coefficient $\left(C_{d}\right)$. Also, for a certain value for the ratio $\left(H_{w} / p\right)$ the $C_{d}$ was observed to give a maximum value when the radius of curvature of the behind top edge was equal to $20 \%$ of the height of the weir.

For $\left(H_{w} / p \leq 0.8\right)$, it is clear that the $C_{d}$ increases slightly, while for $\left(H_{w} / p>0.8\right)$ the $C_{d}$ tangibility increases. This is due to, at high values of discharges, turbulent downstream head structure decrease.

Based on the experimental data and using the simple and multiple linear regression analysis, the best equa- tion for predicting the discharge coefficient $\left(C_{d}\right)$ for round corner weirs as a function of the ratio between head over the crest and the height of weir $\left(H_{w} / p\right)$ can be written in the following form:

$$
C_{d}=\mathrm{A}\left(H_{w} / p\right)^{2}+\mathrm{B}\left(H_{w} / p\right)+\mathrm{C},
$$

in which (A, B and C) are coefficients dependent on the radius of curvature of the behind weir top edge. Their values are given in Table 5, as well as the different values of correlation factor.

Table 5. Values of coefficients $A, B$ and $C$ in Equation 8

\begin{tabular}{cccccc}
\hline Ratio of $r_{d} / p$ & 0.1 & 0.2 & 0.3 & 0.4 & 0.5 \\
\hline A & 0.2989 & 0.2269 & 0.408 & 0.3523 & 0.543 \\
\hline B & -0.0907 & -0.0065 & -0.205 & -0.1066 & -0.3711 \\
\hline C & 0.548 & 0.5518 & 0.5732 & 0.5468 & 0.6004 \\
\hline$R^{2}$ & 0.990 & 0.993 & 0.952 & 0.997 & 0.963 \\
\hline
\end{tabular}

\section{B. Relations between the discharge $(Q)$ and the upstream} head over the crest $\left(H_{w}\right)$

The relationship between the discharge $(Q)$ and the upstream head over the crest $\left(H_{w}\right)$ for all models under study with a curvature of the behind weir top edge is shown in Figure 7. This figure shows the percentage of increase in the discharge $(Q)$, using different radius of curvature of the behind weir top edge to be more than that obtained using the sharp one.

The variation of discharge coefficient $\left(C_{d}\right)$ with respect to head normalized to radius of curvature $\left(H_{w} / r_{d}\right)$ shows that the discharge coefficient is greatly affected by the upstream head over the crest $\left(H_{w}\right)$ and the discharge coefficient value increases with increasing values of $\left(H_{w}\right)$.

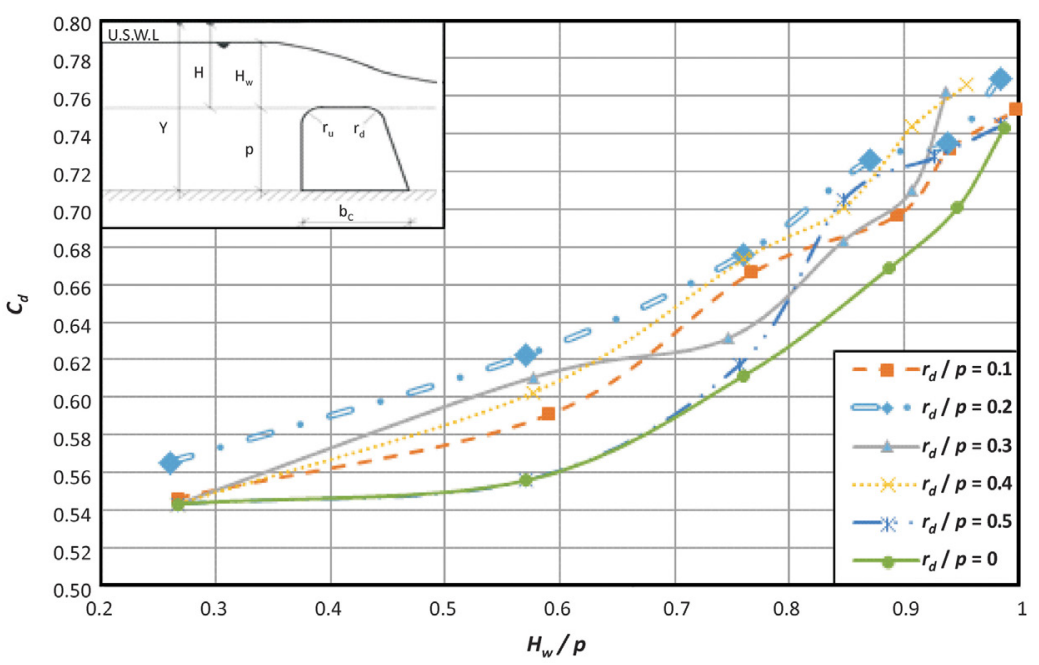

Fig. 6. Relationship between the discharge coefficient and the ratio between head over the crest and the height of weir $\left(H_{w} / p\right)$ for different tested weirs 


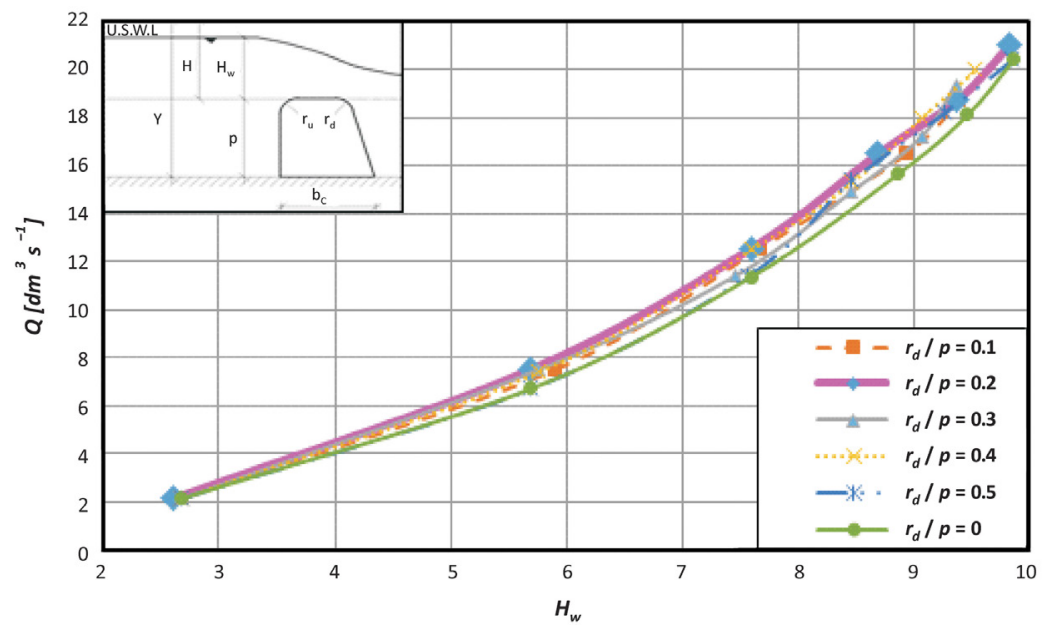

Fig. 7. Relationship between the discharge $(Q)$ and the downstream head over the crest $\left(H_{w}\right)$ for different tested weirs

C. Relations between the discharge coefficient $\left(C_{d}\right)$ and the discharge $(Q)$

The relationship between the $C_{d}$ and the $Q$ for all models under study with curvature of the behind weir top edge is shown in Figure 8. This figure shows the percentage of increase in the $C_{d}$, using different radius of curvature of the behind weir top edge to be more than that obtained using the sharp one.

From this figure it is clear that, at the same value of discharge $(Q)$, the model with a radius of curvature equal to $20 \%$ of the height of the weir gives the maximum value of the discharge coefficient $\left(C_{d}\right)$.

For comparison purposes, Table 6 was constructed, including the obtained values of the percentage of increase in the $C_{d}$ using different curvature of the behind weir top edge more than the sharp one. From the table, it is clear that:

- For all studied discharges, the weirs with a curvature of the behind top edge are more effective

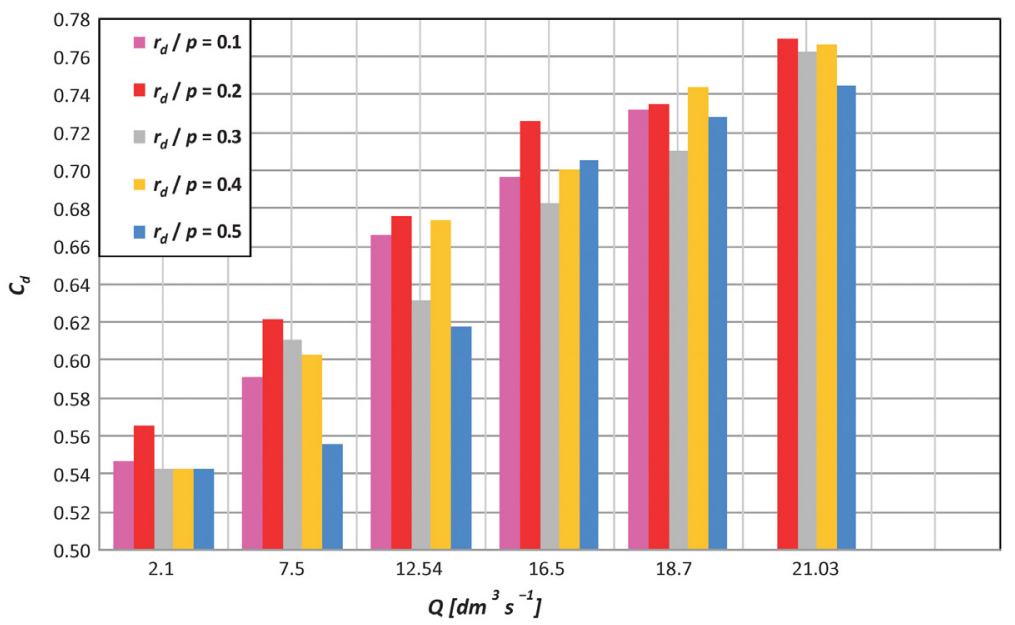

Fig. 8. Relationship between the discharge coefficient $\left(C_{d}\right)$ and the discharge $(Q)$, for different tested weirs

Table 6. Effect of curvature of the front weir top edge on the discharge coefficient $\left(C_{d}\right)$ compared with using the sharp one

\begin{tabular}{|c|c|c|c|c|c|c|c|}
\hline \multirow{2}{*}{ Ratio of $r_{d} / p$} & \multicolumn{6}{|c|}{ Discharge coefficient $C_{d}$ for different values of $Q\left[\mathrm{dm}^{3} \mathrm{~s}^{-1}\right]$} & \multirow{2}{*}{$C_{d}$ increase [in \%] } \\
\hline & $Q=2.1$ & $Q=7.5$ & $\mathrm{Q}=12.5$ & $Q=16.5$ & $Q=17.5$ & $Q=21$ & \\
\hline 0.0 & 0.543 & 0.555 & 0.611 & 0.668 & 0.701 & 0.742 & reference \\
\hline 0.1 & 0.546 & 0.590 & 0.666 & 0.696 & 0.732 & 0.752 & $0.00-8.98$ \\
\hline 0.2 & 0.582 & 0.630 & 0.694 & 0.732 & 0.744 & 0.781 & $0.00-13.6$ \\
\hline 0.3 & 0.543 & 0.6107 & 0.631 & 0.683 & 0.710 & 0.762 & $0.00-9.70$ \\
\hline 0.4 & 0.543 & 0.602 & 0.673 & 0.700 & 0.743 & 0.766 & $0.00-10.1$ \\
\hline 0.5 & 0.543 & 0.555 & 0.617 & 0.705 & 0.727 & 0.744 & $0.00-5.00$ \\
\hline
\end{tabular}




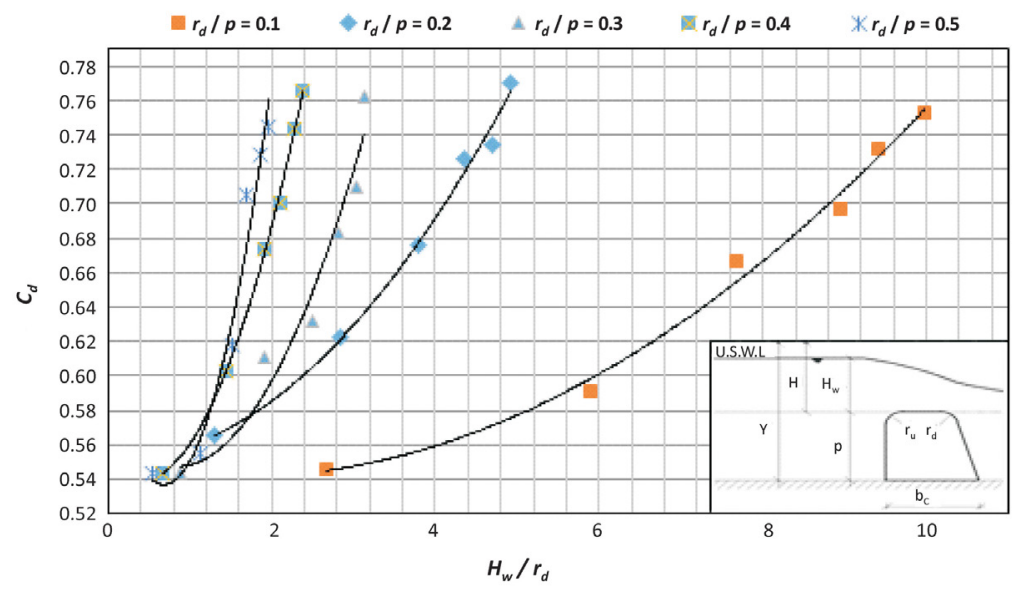

Fig. 9. Relationship between the discharge coefficient $\left(C_{d}\right)$ and the ratio between head over the crest and the radius of curvature of weir $\left(H_{w} / r_{d}\right)$

than the sharp one in increasing the discharge coefficient $\left(C_{d}\right)$;

- The weir model with a radius of curvature equal to $20 \%$ of the height of the weir gives the maximum value of the discharge coefficient $\left(C_{d}\right)$;

- Increasing the ratio between the radius of curvature and the height of the weir by more than $20 \%$, decreases the value of the discharge coefficient $\left(C_{d}\right)$;

- When the behind top edge of the weir is curved, the discharge coefficient increased up to $14 \%$, which is in agreement with the results of Schmocker et al. (2011) and Fawer (1937).

D. Relations between the discharge coefficient $\left(C_{d}\right)$ and the ratio between head over crest and curvature at downstream $\left(H_{w} / r_{d}\right)$

The relationship between the $C_{d}$ and the ratio $\left(H_{w} /\right.$ $r_{d}$ ) for all models under study with a curvature of the behind top edge is shown in Figure 9. From this figure it is clear that the increase in the ratio $\left(H_{w} / r_{d}\right)$ value causes an increase in the $C_{d}$ value for the same height of weir. Also, for a further increase of the ratio $\left(H_{w} / r_{d}\right)$ the percentage of increase in the $C_{d}$ increases. At the same time, it is observed that the curvature of the behind top edge of the weir allows water to flow more easily and increases the discharge capacity. Moreover, the hydraulic characteristics of the round corner weir depend mainly on the dimensionless total downstream head $\left(H_{w} / r_{d}\right)$ independent of weir height $(p)$.

Based on the experimental data and using the simple and multiple linear regression analysis, the best equation for predicting the $C_{d}$ for round corner weirs as a function of the ratio $\left(H_{w} / r_{d}\right)$ can be written in the following form:

$$
C_{d}=\mathrm{A}\left(H_{w} / r_{d}\right)^{2}+\mathrm{B}\left(H_{w} / r_{d}\right)+\mathrm{C},(9)
$$

in which (A, B and C) are coefficients dependent on the radius of curvature of the behind weir top edge. Their values are given in Table 7, as well as the different values of correlation factor.

Table 7. Values of coefficients $A, B$ and $C$ in Equation 9

\begin{tabular}{cccccc}
\hline Ratio of $r_{d} / p$ & 0.1 & 0.2 & 0.3 & 0.4 & 0.5 \\
\hline A & 0.003 & 0.009 & 0.0368 & 0.0564 & 0.135 \\
\hline B & -0.009 & -0.0013 & -0.061 & -0.042 & -0.185 \\
\hline C & 0.548 & 0.551 & 0.573 & 0.546 & 0.600 \\
\hline $\mathrm{R}^{2}$ & 0.990 & 0.993 & 0.952 & 0.997 & 0.963 \\
\hline
\end{tabular}

\section{Conclusions}

From the present study and its experimental results the following main conclusions can be drawn:

1. The ratio $\left(H_{w} / r\right)$ increases, the discharge coefficient increases.

2. Curvature of the front or behind top edge of a weir enhances the flow and increases the discharge capacity.

3. The ratio between the weir height and the top edge curvature of the weir has a significant influence on the discharge coefficient.

4. The radius of curvature of the front top edge of a clear over-fall weir has a small effect on the discharge coefficient, while using curvature of the behind top edge caused a significant increase in the discharge coefficient.

5. When the front top edge of the weir is curved, the discharge coefficient increases up to $8 \%$.

6. When the behind top edge of the weir is curved, the discharge coefficient increases up to $14 \%$.

7. The discharge coefficient has a maximum value when the radius of curvature in the front and behind top edge of weir is equal to $20 \%$ of the height of the weir. 


\section{Nomenclature}

$A$ - coefficient depends on the radius of curvature for the upstream or downstream top corners of a clear over-fall weir

$B$ - coefficient depends on the radius of curvature for the upstream or downstream top corners of a clear over-fall weir

$C$ - coefficient depends on the radius of curvature for the upstream or downstream top corners of a clear over-fall weir

$H$ - upstream total head of flow

$L$ - length of the weir

$R$ - radius of cylindrical weir

$Y$ - water depth upstream the weir

$Q$ - discharge capacity

$C_{d_{-}}$coefficient of discharge for free flow

$H_{w-}^{d-}$ head over crest

$g$ - gravitational acceleration

$p$ - weir height

$q$ - discharge per unit width of gate or channel

$r_{d-}$ downstream edge radius of curvature

$r_{u-}$ upstream edge radius of curvature

$\theta$ - vertex angle

$\mu$ - dynamic viscosity of water

$\rho$ - density of water

$\sigma$ - surface tension of water

\section{References}

Abou-Rehim M.A., 1991, Flow over weirs with practical profile, Alexandria Eng. J. 30(4).

Al-Babely E.A.G., Al-Muhammad A.A.W., Al-Dabbagh M.A. 2011, Overflow characteristic of cylindrical shape crest weirs over horizontal bed, Tikrit J. Eng. Sci. 18(4): 29-39.

Amin K.A., 2005, A comprehensive study concerning the effect of curved weir shapes on the flow characteristics and bed topography [PhD Thesis], Assiut University, Assiut, Egypt, 266 pp.

Arvanaghi H., Mahtabi G., 2015, Discharge coefficient of semicircular-trapezoidal weir, Int. J. Agri. Biosci. 4(5): 192-195.

Ashour M.A., 1974, Effect of surface slope on the ratio of submersion for the standing wave weir [Master Thesis], Faculty of Engineering, Assiut University, Assiut, 56 pp.

Ashour M.A., Amin K.A., Abu-Zeid T.S., Hassan R., 2016, Effect of the free over fall weirs top corners curvatures on the discharge coefficient, Int. J. Constr. Res. Civil Eng. (IJCRCE) 2(4): 1-11.
Bazin H., 1898, Expériences nouvelles sur lécoulement par déversoir [Recent experiments on the flow of water over weirs], Ann. Ponts Chaussées 68(2): 151-265 [in French].

Caroline L.L., Afshar N.R., 2014, Effect of types of weir on discharge, UNIMAS J. Civil Eng. 5(2): 35-40.

Cline C.G., 1935, Discharge formula and tables for sharpcrested suppressed weirs, Trans. Am. Soc. Civ. Eng. (ASCE) 100(1): 396-413.

Creager W.P., 1917, Engineering of masonry dams, Wiley, New York, 237 pp.

Fawer C., 1937, Etude de quelques ecoulements permanents à filets courbes (Study of some steady flows with curved streamlines) [Thesis], Universite de Lausanne, Imprimerie La Concorde, Lausanne, 127 pp (in French).

Ghazizadeh F., Moghaddam M.A., 2016, An experimental and numerical comparison of flow hydraulic parameters in circular crested weir using Flow3D, Civil Eng. J. 2(1): 23-37.

Haghiabi A.H, 2012, Hydraulic characteristics of circular crested weir based on Dressler theory, Biosyst. Eng. 112(4): 328-334.

Henderson F.M., 1966, Open channel flow, Macmillan, New York, $522 \mathrm{pp}$.

Jalil S.A, Ibrahim S.S., Jafer R.A., 2014, Surface roughness effects on discharge coefficient of broad crested weir, Res. J. Appl. Sci., Eng.Technol. 7(24): 5227-5233.

Kumar S., Ahmad Z., Mansoor T., Himanshu S.K., 2013, A new approach to analyze the flow over sharp-crested curved plan form weirs, Int. J. Recent Technol. Eng. (IJRTE) 2(1): 24-28.

Leliavsky S., 1959, Irrigation and hydraulic design. Vol. 1: General principles of hydraulic design, Chapman and Hall, London, $492 \mathrm{pp}$.

Madadi M.R., Dalir A.H.., Farsadizadeh D., 2013, Control of undular weir flow by changing of weir geometry, Flow Meas. Instrum. 34: 160-167.

Parsaie H.T.A., Haghiabi A.H,, Saneie M., Torabi H., 2016, Predication of discharge coefficient of cylindrical weirgate using adaptive neuro fuzzy inference systems (ANFIS), Front. Struct. Civ. Eng. 1(1): 1-12.

Ramamurthy A.S., Vo N.D., 1993a, Application of Dressler theory to weir flow, J. Appl. Mech. 60(1): 163-166.

Ramamurthy A.S., Vo N.D., 1993b, Characteristics of circular crested weir, J. Hydraul. Eng. 119(9): 1055-1062.

Riyadh H.M., 2013, Calibrating the discharge coefficient of rectangular with quarter circular edge crested weir, J. Karbala Univ. Scientific 11(2): 64-73.

Schmocker L., Halldórsdóttir B.R., Hager W.H., 2011, Effect of weir face angles on circular-crested weir flow, J. Hydraul. Eng. 137(6): 637-643.

Woodburn J.G., 1932, Tests of broad-crested weirs, Trans. Am. Soc. Civ. Eng. (ASCE) 96: 387-416. 